\title{
Ellagic acid: an alternative for antifungal drugs resistance in HIV/AIDS patients with oropharyngeal candidiasis
}

\author{
Satutya Wicaksono ${ }^{1}$, Fianza Rezkita ${ }^{1}$, Fadhilah N. Wijaya ${ }^{1}$, Alexander P. Nugraha ${ }^{2}$, Saka Winias ${ }^{3}$ \\ ${ }^{1}$ Faculty of Dental Medicine, Universitas Airlangga, Surabaya, Indonesia \\ ${ }^{2}$ Dental and Biomaterial Research Group, Faculty of Dental Medicine, Universitas Airlangga, Surabaya, Indonesia \\ ${ }^{3}$ Department of Oral Medicine, Faculty of Dental Medicine, Universitas Airlangga, Surabaya, Indonesia
}

\begin{abstract}
Oropharyngeal candidiasis (OPC) is considered the most common fungal infection in human immunodeficiency virus (HIV)/acquired immunodeficiency syndrome (AIDS) patients. Antifungal drug, azole group, is the preferred treatment. However, the long-term use of antifungal drug as prophylaxis and therapy for OPC may lead to a compromised side effects and drug resistance. Nowadays, the prevalence of antifungal Candida albicans resistance is approximately $56.7 \%$. Ellagic acid (EA) presents broad spectrum of antifungal activities. Based on previous studies, EA can act as natural antifungal agent. It also helps enhancing oral mucosal innate immunity. This review explores the antifungal activity of EA as an alternative for antifungal drugs resistance in HIV/AIDS patients with OPC. A web-based search was conducted via PubMed, NCBI, Scopus, ScienceDirect, and ResearchGate databases, with "antifungal resistance", "ellagic acid", "HIV/AIDS", and "OPC" as the keywords. EA is a dimeric derivative of gallic acid that is found in several plants. EA can induce the expression of hBD2 and SLPI in the oral mucosa. Those proteins play a pivotal role in immunomodulation and anti-inflammation of oral microenvironment innate immunity, which inhibit several opportunistic pathogens and microbes, including Candida. Furthermore, EA also inhibits ergosterol biosynthesis (EB), which is the primary component of fungi cell membrane. EA breakdown fungal membrane permeability and enzyme activity, leading to cessation of fungal growth. EA presents antifungal activity in HIV/AIDS patients with OPC; thus, it can be used as an alternative in antifungal drug resistance.
\end{abstract}

HIV AIDS Rev 2020; 19, 3: 153-156

DOI: https://doi.org/10.5114/hivar.2020.98007

Key words: antifungal drugs, drugs resistance, ellagic acid, HIV/AIDS, oropharyngeal candidiasis.

\section{Introduction}

The most progressive growth rate of human immunodeficiency virus (HIV)/acquired immunodeficiency syndrome (AIDS) in whole Asian continent occurs in Indonesia [1]. It is estimated that about 4.1-6.7 million people are living with HIV/AIDS (PLWHA) in Asia-Pacific region [2]. In 2017, East Java was one of the provinces in Indonesia, which was rated the second highest HIV/AIDS prevalence, with nearly 39,633 PLWHA [3]. The trend of AIDS-related mortality is declining in almost all high-risk countries, but Indonesia is an exception [4]. In Indonesia, there are some provinces with a significant growth rate of HIV/AIDS cases. The highest cumulative percentage from 1987 to December 2017 was noted in a group of individuals between 20 and 29 years old (32.5\%) [5]. During the HIV/AIDS onset, oral manifestation commonly
Address for correspondence: Saka Winias, DDS, MSc, Faculty of Dental Medicine, Airlangga University, Surabaya, Indonesia, e-mail: saka.winias@fkg.unair.ac.id
Article history:

Received: 09.07.2019

Received in revised form: 16.08.2019

Accepted: 28.08.2019

Available online: 30.06 .2020
International Journal of HIV-Related Problems

HIV \& AIDS

R e vi e w 
occurs due to immunodeficiency condition. Oral microbiome turns to opportunistic pathogens that can lead to oral manifestations closely related to HIV/AIDS, such as oral candidiasis $(\mathrm{OC})[3,6]$, oral hairy leukoplakia $(\mathrm{OHL})[7,8]$, linear gingival erythema (LGE) [4, 9], necrotizing ulcerative gingivitis (NUG), and necrotizing ulcerative periodontitis (NUP) [10]. In addition, through the HIV/AIDS onset, the use of antiretroviral therapy (ART) and psychological stress can trigger xerostomia in PLWHA [11, 12]. Among other oral manifestations in HIV/AIDS patients, the most common is OC [3]. Prolonged duration of HIV/AIDS and untreated OC can lead to further OC progression causing oropharyngeal candidiasis (OPC) [6], which commonly occurs in late stage of HIV/AIDS [13]. OPC is often localized and typically caused by Candida albicans, which is an opportunistic pathogen microflora along human gastrointestinal tract [14]. OPC occurs in approximately $90 \%$ of PLWHA $[15,16]$, and although the incidence of OPC has declined due to the use of ART, this disease remains a main concern in PLWHA with limited local-resources or among individuals, who have acquired mycological resistance or suffered a poor immunologic response, which greatly reduce their quality of life [17]. OPC may also be an early indicator of HIV infection and may predict progressive immunodeficiency because it does not have a gender or race predilection. Instead, the occurrence of OPC relate to HIV viral load and cluster of differentiation 4+ (CD4+) level in PLWHA [14-17]. The use of antifungal drugs is one of the managements of OPC in PLWHA. Most common drugs of choice for HIV/AIDS patients with OPC are fluconazole for topical application and nystatin for oral administration. Fluconazole could be used as prophylaxis as well as long-term therapy in OPC patients. However, long-term use of antifungal drugs in OPC cases could lead to antifungal drug resistance [17]. Based on candidemia surveillance study, there was an increasing number of antifungal drug resistance from 2008 (4.2\%) to 2014 (7.8\%), with a prevalence of antifungal resistance, especially C. albicans, of approximately $56.7 \%$ [18]. The use of fluconazole is associated with Candida species, but long-term use can lead to a decreased sensitivity of Candida to fluconazole. Factors associated with this decrease are the change of Candida species from albicans to non-albicans and its resistance to azole group [19-21]. Further investigation is required to obtain a new compound that can overcome this problem. Ellagic acid (EA) is a dimeric derivative of gallic acid found in various plants (e.g., pomegranates and walnuts). Previous study by Promsong et al. reported that EA have the capability to enhance mucosal innate immunity, including oral innate immunity, by EA ability to increase the expression of oral innate immune mediators, especially hBD2 and secretory leukocyte protease inhibitor (SLPIs) [15]. Therefore, the aim of this review was to present the antifungal activity of EA as an alternative to antifungal drugs resistance in HIV/AIDS patients with OPC.

\section{Methods and search strategy}

The review article was based on the preferred reporting items for systematic reviews and meta-analyses 2009 (PRISMA
2009), which can be found on http://www.prisma-statement.org. This independent literature search was performed by our team using different databases, including PubMed, NCBI, Scopus, ScienceDirect, and ResearchGate, with the keywords, such as "OPC", "HIV/AIDS", "antifungal resistance", and "EA". The criteria for data collection included: 1) observational study and clinical trials; 2) texts in English; 3) publications from the past six years from 2013 to 2019; 4) free of charge and full-texts available. Any related studies were also examined to promote the main study.

\section{Results and discussion}

\section{Oral innate immunity}

Innate immunity plays a pivotal role in the maintenance of oral homeostasis and the regulation of oral infection and consist of both cells and soluble protein-mediated immunity. Mucosal innate immune cells comprise of a diverse group of cells, including antigen presenting cells (APCs) with dendritic cells (DCs), and macrophages, which play an important role in the induction and regulation of immune responses at mucosal surface [24]. Oral innate immunity consists of secretory immunity of the salivary glands, innate immune factors in saliva, epithelial cells, epithelial cell-derived innate immune agents, innate immune cells including Langerhans cells (LCs), intraepithelial lymphocytes, tissue macrophages, and commensal and endogenous pathogens $[13,24]$. Oral stratified squamous cell epithelial is a part of oral innate immunity that plays a crucial role in maintaining homeostasis of oral cavity and regulating oral infection and cancer [13, 15]. These cells provide not only physical but also chemical barriers against invasion of various microorganisms [13]. They produce various microbial peptides, including hBD2 and SLPIs, which provide growth inhibition for several opportunistic microorganisms, such as Candida. In addition, the cells also secrete high concentrations of cytokines and chemokines like TNF- $\alpha$, IL-2, and IL-4, as pro-inflammatory and immunoregulatory factors. These mediators activate and regulate immune responses of both innate and adaptive immune systems and prevent colonization and invasion of a pathogen on the mucous membrane surface. Therefore, the impairment of this system leads to opportunistic infection [15].

\section{Oral innate immunity in people live with HIV/AIDS}

HIV infection can lead to direct and indirect impairment towards systemic and local innate immunity, which induces oral opportunistic infections and malignancies. HIV directly attack the adaptive immunity, especially CD4+ T-cells. The infection can indirectly affect the innate immunity through microbial translation, inflammation, and immune activation, whereas immune activation reduce the number of monocytes, natural killer (NK), and innate lymphoid cells (ILCs), which consequently leads to 
poor innate and adaptive immunity. This infection can directly affect the lining of oral epithelium that affect the cell structure and function, causing an impairment of innate immunity and promoting colonization of opportunistic pathogen microbes [24].

\section{Ellagic acid}

EA is a type of polyphenolic compound also a dimeric derivative of gallic acid that is widely distributed in various plants, such as pomegranate, walnut, blackberries, raspberries, and strawberries that has antioxidative, antibacterial, anti-inflammatory, and antifungal activities $[22,25]$. EA could be used as drug for alcohol abuse because EA decrease toxin caused by high intensity alcohol in the body. The anti-inflammatory effects of EA could inhibit cyclooxygenase (COX), nitric oxide synthase (iNOS), tumor necrosis factor-alpha (TNF- $\alpha$ ) and interleukin-6 (IL-6) down- regulation. The EA possessed an anti-carcinogenic activity by inhibits carcinogenesis and mutagenesis. It also has anti-hyperlipidemic effects by diminish low-density lipoprotein (LDL) oxidation and anti-diabetic effects by regulating the blood glucose significantly [23].

\section{Ellagic acid enhancement of oral innate immunity}

EA significantly induces the expression of hBD2 and SLPI without cytotoxicity at both transcriptional and translational levels in vivo [13] as well as the expression of pro-inflammatory and immunoregulatory cytokines and chemokines. hBD2 is a small cationic peptide expressed in many human epithelial tissues, such as oral stratified squamous cell epithelia, and presents antimicrobial activity against pathogens, including C. albicans. Additionally, hBD2 enhances host immune responses and holds many activities related to the immune system, such as chemotactic activity for dendritic cells and memory $\mathrm{T}$ cells, and the production of cytokines and chemokines. SLPI is a serine protease inhibitor expressed by mucosal epithelial cells, produced at different mucosal sites. It participates in innate immune response by inhibiting excessive proteases, showing anti-inflammatory properties. Candida is one of the fungals that produce protease. Furthermore, SLPI can inhibit either colonization or infection of Candida [24]. In low concentration of EA, the production of IL- $1 \beta$ is being induced. In response to EA, oral epithelial cells significantly secrete various cytokines and chemokines, such as IL- $1 \beta$ and TNF- $\alpha$, which are able to stimulate the production of other cells, leading to cascades, in which the second or the third may mediate the biologic effects of the first, and the elevation of expression of IL$1 \beta$ may influence the elevation of expression of hBD2 [15]. IL- $1 \beta$ is a unique compound, which has an important biological activity of activation of T lymphocytes by enhancing the production of IL-2 and the expression of IL-2 receptors.
IL-2 itself has a function in activation of NK cells, B cells, cytotoxic T cells, and macrophages to move to the site of infection. Overall, the upregulated expression of hBD2 and SLPI, and other cytokines and chemokines in response to EA, may imply that consuming EA-rich fruits or using topical agent products, such as EA-containing mouthwash, might help to maintain oral homeostasis in immunocompromised patients [15].

\section{Ellagic acid inhibits ergosterol biosynthesis}

Ergosterol is an important component in the structure of fungal membrane, which maintain the stability of membrane structure and regulate fluid homeostasis in fungal membranes. It regulates the activity of enzyme in the membrane and acts as a carrier of substance for the fungal. Ergosterol deficiency can cause fungal membrane dysfunction or even damage, which leads to clinical antifungal effect. An experiment conducted by Li et al. using EA in vitro and verified by in vivo may significantly decrease ergosterol by inhibiting the CYP51 enzyme. CYP51 is the main enzyme in sterol biosynthesis pathway. Based on this experiment, treatment with EA can result in a significant decrease in the activity of CYP51. The mechanism of azole group inhibits ergosterol biosynthesis, which further impedes 14-a-demethylase of fungal cytochrome P450 enzymes. This 14- $\alpha$-demethylase converts lanosterol to ergosterol. It modifies fungal membrane permeability and inhibits enzyme activity on fungal membrane, which leads to a cessation of fungal growth [25].

\section{Conclusions}

Prolonged exposure to fluconazole as antifungal agent can increase fluconazole resistance in PLWHA. Alternative treatment using another compound is needed to improve the quality of life of PLWHA. EA, that can be found in berries, presents the ability to induce $\mathrm{hBD} 2$ and SLPI expression as oral mucosal innate immunity enhancement, and to inhibit ergosterol biosynthesis as antifungal activity in HIV/ AIDS patients with OPC; therefore, it can be an alternative in antifungal drugs resistance. Further research is required to analyze the potential of EA as an antifungal agent.

\section{Acknowledgment}

The authors would like to appreciate the support of the Faculty of Dental Medicine, Airlangga University, as the facility provider.

\section{Conflict of interest}

The authors declare no conflict of interest with respect to the research, authorship, and/or publication of this article. 


\section{References}

1. Joint United Nations. Programme on HIV/AIDS (UNAIDS). Overview HIV/AIDS Infection in Indonesia. Joint United Nations; 2016. Available from: http://www.unaids.org/en/regionscountries/countries/indonesia (Accessed: 21.01.2019).

2. Avert Organization Global Information and Education on HIV and AIDS. HIV and AIDS in Asia \& The Pasific Regional Overview. Available from: https://www.avert.org/professionals/hiv-aroundworld/asia-pacific/overview (Accessed: 1.04.2019).

3. Mensana MP, Ernawati DS, Nugraha AP, Soebadi B, Triyono EA, Husada D. Oral candidiasis profile of the Indonesian HIV-infected pediatric patients at UPIPI Dr. Soetomo General Hospital, Surabaya, Indonesia. HIV AIDS Rev 2018; 17: 272-277.

4. Mensana MP, Nugraha AP, Ernawati DS, Soebadi B, Triyono EA, Husada D. Sensitivity and specificity of linear gingival erythema as immune suppression marker in pediatric HIV-infected at UPIPI soetomo general hospital Surabaya, Indonesia. Indian J Public Health Res Dev 2019; 10: 575-580.

5. Directorate of Prevention and Disease Control, Republic of Indonesia Health Ministry. Progress Report Situation of HIV/AIDS in Indonesia. Directorate of Prevention and Disease Control; 2017. Available from: http://siha.depkes.go.id/portal/files_upload/Laporan_HIV_ AIDS_TW_4_Tahun_2017_1_.pdf (Accessed: 1.04.2019).

6. Nugraha AP, Ernawati DS, Parmadiati AE, Soebadi B, Triyono EA, Prasetyo RA. Prevalence of Candida species in oral candidiasis and correlation with CD4+count in HIV/AIDS patients at Surabaya, Indonesia. J Int Dent Med Res 2018; 11: 81-85.

7. Parmadiati AE, Ernawati DS, Soebadi B, Nugraha AP, Triyono EA, Prasetyo RA. Correlation oral hairy leukoplakia and CD4+ counts in HIV/AIDS patients at Dr. Soetomo hospital Surabaya, Indonesia 2014. J Int Dent Med Res 2017; 10: 162-165.

8. Mensana MP, Nugraha AP, Ernawati DS, Triyono EA, Husada D, Prasetyo RA. Correlation of oral hairy leukoplakia, HAART and CD4+ in HIV-infected pediatric patients at UPIPI Soetomo Hospital Surabaya, Indonesia. J Int Dent Med Res 2019; 12: 165-169.

9. Nugraha AP, Ernawati DS, Parmadiati EA, Soebadi B, Triyono EA, Prasetyo RA. Correlation linear gingival erythema, Candida infection and CD4+ counts in HIV/AIDS patients at UPIPI RSUD Dr. Soetomo Surabaya, East Java, Indonesia. J Int Dent Med Res 2017; 10: 322-326.

10. Nugraha AP, Triyono EA, Prahasanti C, Sufiawati I, Prasetyo RA, Ernawati DS. The correlation of pathognomonic periodontal manifestation with CD4+ level in people live with human immunodeficiency virus/acquired immunodeficiency syndrome in a Tertiary Hospital, Surabaya, Indonesia. J Int Oral Health 2019; 11: 137-140.

11. Nugraha AP, Ernawati DS, Harijanti K, Parmadiati AE. Psychological stress induced xerostomia and hyposalivation: the case study in Indonesian female patient. J Int Dent Med Res 2019; 12: 216-219.

12. Nizamuddin I, Koulen P, McArthur C. Contribution of HIV infection, AIDS, and antiretroviral therapy to exocrine pathogenesis in salivary and lacrimal glands. J Int Mol Sci 2018; 19: 2747.

13. Nittayananta W. Oral fungi in HIV: challenges in antifungal therapies. Oral Dis 2016; 22 Suppl 1: 107-113.

14. Osaigbovo I, Lofor PV, Oladele RO. Fluconazole resistance among oral Candida isolates from people living with HIV/AIDS in a Nigeria Tertiary Hospital. J Fungi (Basel) 2017; 3: 69.

15. Promsong A, Chung WO, Satthakarn S, Nittayananta W. Ellagic acid modulates the expression oral innate immune mediators: potential role in mucosal protection. J Oral Pathol Med 2015; 44: 214-221.

16. Patil S, Majumdar B, Sarode S, Sarode G, Awan K. Oropharyngeal candidiasis in HIV-infected patients - an update. Front Microbiol 2018; 9: 980 .

17. Nugraha AP, Ernawati DS, Parmadiati AE, Soebadi B, Prasetyo RA, Triyono EA. Study of drug utilization within an anti-fungal therapy for HIV/AIDS patients presenting oral candidiasis at UPIPI RSUD, Dr. Soetomo hospital, Surabaya. J Int Dent Med Res 2018; 11: 131-134. 18. Perlin D, Rautemaa-Richardson R, Alastruey-Izquierdo A. The global problem of antifungal resistance: prevalence, mechanisms, and management. Lancet Infect Dis 2017; 17: e383-e392.

19. Sobel JD, Akins RA. The role of resistance in Candida infections: epidemiology and treatment. In: Antimicrobial Drug Resistance: Clinical and Epidemiological Aspects. Volume 2, 2017; 1075-1097.

20. Whaley SG, Berkow EL, Rybak JM, Nishimoto AT, Barker KS, Rogers PD. Azole antifungal resistance in Candida albicans and emerging non-albicans candida species. Front Microbiol 2017; 7: 2173.

21. Salari S, Khosravi AR, Mousavi SA, Nikbakht-Brojeni GH. Mechanisms of resistance to fluconazole in Candida albicans clinical isolates from Iranian HIV-infected patients with oropharyngeal candidiasis. J Mycol Med 2016; 26: 35-41.

22. Menaa F, Menaa A. Skin photoprotection by polyphenols in animal models and humans. Polyphenols in Human Health and Disease 2014; 831-838.

23. Usta C, Ozdemir S, Schiariti M, Puddu P. The pharmacological use of ellagic acid-rich pomegranate fruit. Int J Food Sci Nutr 2013; 64: 907-913.

24. Nittayananta W, Tao R, Jiang L, Peng Y, Huang Y. Oral innate immunity in HIV infection in HAART era. J Oral Pathol Med 2016; 45: 3-8.

25. Li Z, Guo X, Dawuti G, Aibai S. Antifungal activity of ellagic acid in vitro and in vivo. Phytotherapy Res 2014; 29: 1019-1025. 